Article

\title{
Purification and Structural Analysis of the Effective Anti-TMV Compound ع-Poly-L-lysine Produced by Streptomyces ahygroscopicus
}

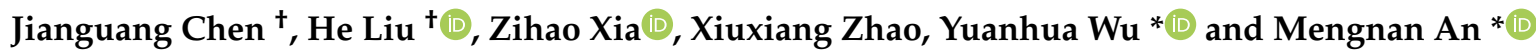 \\ College of Plant Protection, Shenyang Agricultural University, Shenyang 110866, Liaoning, China; \\ chenjianguang2010@126.com (J.C.); m18240156631_2@163.com (H.L.); zihao8337@syau.edu.cn (Z.X.); \\ zhaoxx0772@163.com (X.Z.) \\ * Correspondence: wuyh09@syau.edu.cn (Y.W.); anmengnan1984@163.com (M.A.); \\ Tel.: +86-24-8848-7148 (Y.W.); +86-135-1603-1240 (M.A.) \\ + These authors contributed equally to this work.
}

Received: 3 March 2019; Accepted: 21 March 2019; Published: 23 March 2019

\begin{abstract}
Microbial secondary metabolites produced by actinomycetes are important natural products widely applied to control plant diseases. A variety of actinomycetes were isolated from soil samples collected from Tianzhu Mountain in Shenyang, China. A Streptomyces strain Shenyang Tianzhu (STZ) exhibits effective antiviral activity against Tobacco mosaic virus (TMV). The isolate was identified as Streptomyces ahygroscopicus based on its cultural, morphological, physiological, biochemical characteristics as well as the phylogenetic analysis using 16S rRNA sequences. To obtain the pure anti-TMV compound from Streptomyces STZ, the culture broth was subjected to Amberlite IRC-50 ion-exchange resin, SX-8 macroporous adsorption resin and Sephadex G-25 gel column chromatography. The purified active compound was confirmed to be $\varepsilon$-poly-L-lysine ( $\varepsilon$-PL), with molecular mass in the range of $3454-4352$ Da by structural analysis with infrared (IR), matrix-assisted laser desorption ionization-time-of-flight MS (MALDI-TOF), thin-layer chromatography (TLC) and high-resolution magic angle spinning nuclear magnetic resonance (HR-MAS NMR). The protective and curative effects of the purified compound $\varepsilon$-PL were tested and the results showed that the compound exhibited significant protective and curative activity against TMV. The potential application of $\varepsilon$-PL as an efficient anti-plant virus agent was expected.
\end{abstract}

Keywords: Streptomyces ahygroscopicus; anti-TMV activity; isolation and purification; structural determination; $\varepsilon$-poly-L-lysine

\section{Introduction}

Plant virus diseases cause considerable economic losses in cereal and horticulture production worldwide every year [1]. Tobacco mosaic virus (TMV) is capable of infecting more than 885 plant species in 65 families [2,3]. Chemical pesticides and insecticides play important roles in controlling virus disease, but the antiviral efficacy and effective duration of action are still limited in the fields. Therefore, development and commercialization of highly effective antiviral agents are expected.

Plant virus inhibitors from metabolites of microbes have been considered as a potential alternative for chemical pesticides, which have become an increasing research spotlight. These bio-agents have various advantages in the respect of low mammalian toxicity, biodegradability, good environmental compatibility and a unique mode of action [4]. Several bio-agents exhibit antiviral activity against TMV have been previously reported. Ningnanmycin is an effective anti-plant virus agent that was isolated from the fermentation broth of Streptomyces noursei var. xichangensis. It effectively inhibited assembly of virions by inhibiting the polymerization of TMV coat protein $(\mathrm{CP})$ in vitro and systemically 
induced the accumulation of pathogenesis-related proteins (PRs) [5]. Cytosinpeptidemycin (CytPM) is a registered antibiotic for agriculture from Agriculture Ministry of China, which was produced by Streptomyces ahygroscopicus isolated from soil samples of Liaoning Province, China. It displays a broad antiviral activity against many plant viruses, such as TMV and rice stripe virus (RSV) [6-8]. Furthermore, CytPM has been used to control southern rice black-streaked dwarf virus (SRBSDV), and has been shown to induce stress and defense responses, such as expression of heat shock protein (Hsp) and pathogenesis-related protein $5(\mathrm{PR}-5)$ [8]. Tan et al. reported an exocellular polysaccharide (EP) from an endophytic fungus (Phomopsis sp FJBR-11) showed a significant inhibition against TMV at a half-maximal inhibitory concentration (IC50) of $1.08 \mu \mathrm{g} / \mathrm{mL}$ [9]. Additionally, studies have shown that a novel glycoprotein (GP-1) from Streptomyces kanasensis can induce systemic resistance (ISR) and exhibits extensive inhibitory effect on TMV infection [10]. However, barely any of the biological agents have been successfully registered as anti-viral agent and widely applied in the field. Therefore, discovering novel, effective, practical, and environmentally safe antiviral agents remains an urgent task to be developed.

In the present study, Streptomyces strain STZwas isolated from the soil of Tianzhu Mountain in Liaoning Province, China, and showed significant anti-TMV activity. Here, we performed polyphasic taxonomic analysis of Streptomyces STZ. Moreover, a novel anti-TMV compound $\varepsilon$-poly-L-lysine $(\varepsilon-P L)$ produced by the strain was purified by various chromatographic techniques, and its structure was determined by various spectral analysis. It is reported that $\varepsilon$-PL has been widely used as a natural food preservative, interferon inducer, drug delivery vehicle, and gene delivery vector, due to antibacterial activity, low toxicity, biodegradability, and thermal stability [11-14]. In this study, the potential application of $\varepsilon$-PL as an efficient anti-plant virus agent was proposed first time.

\section{Results}

\subsection{Isolation, Morphological and Cultural Characteristics of Streptomyces STZ}

Total 69 actinomycete strains were isolated from 34 soil samples based on colony morphology and stability in subculture. Inhibitory activities of fermentation cultures against TMV using the isolated Streptomyces strains were assessed by the half-leaf method and the results indicated that fermentation of Streptomyces strain STZ exhibited the strongest anti-TMV effect with inhibition rate of $88.7 \pm 6.8 \%$ (Figure 1). Streptomyces STZ showed excellent growth with abundant brownish to greyish brown aerial mycelia on ISP2 and Bennett media, showed moderate growth on ISP4 and ISP5 media with a clam white to light brown aerial mycelium after 14 days of incubation at $28^{\circ} \mathrm{C}$. No soluble diffusible pigments were observed on the tested media. The color of the substrate mycelium was light-brown on ISP2, yellow-gray on ISP4, and light mango brown on ISP5.
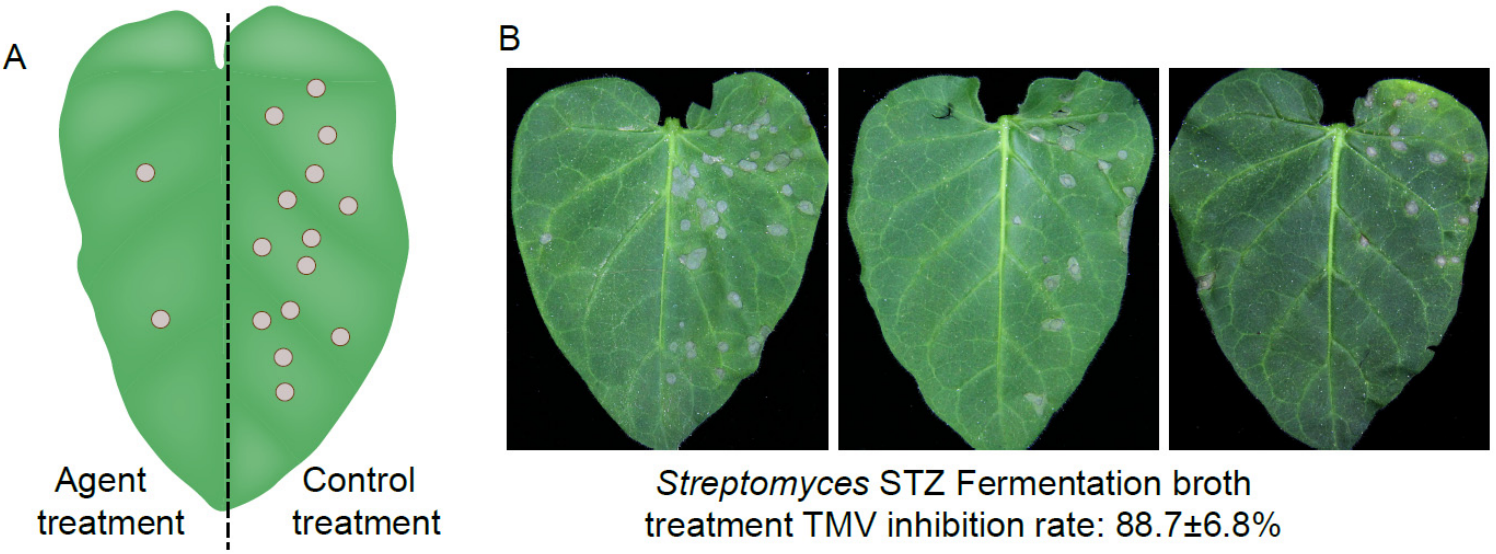

Streptomyces STZ Fermentation broth treatment TMV inhibition rate: $88.7 \pm 6.8 \%$

Figure 1. (A) Schematic representation of half-leaf method to study the anti-viral effect of the agent using N. glutinosa plants; (B) Inhibition effect of Streptomyces STZ fermentation broth against the TMV. 


\subsection{Physiological and Biochemical Characteristics}

The physiological and biochemical properties of Streptomyces STZ are shown in Table 1. Results revealed that it was able to reduce nitrate and hydrolyze starch, gelatin and cellulose but that hydrogen sulfide was not produced. The optimal growth temperature was $28^{\circ} \mathrm{C}$, and growth was inhibited at $50{ }^{\circ} \mathrm{C}$. Strain STZ showed high tolerance to $\mathrm{NaCl}$ including good growth on medium supplemented with $\mathrm{NaCl}$ up to $5 \%$, poor growth at $7 \%$, and no growth at $10 \%$. Utilization of various carbon sources by the isolate indicated that it could grow on D-glucose, sucrose, starch, L-arabinose, D-fructose, galactose, D-mannitol, D-Xylose, inositol and maltose but not L-rhamnose and raffinose.

Table 1. Physiological and biochemical characteristics of the strain STZ.

\begin{tabular}{cccc}
\hline Tests & Result & Tests & Result \\
\hline Biochemical tests: & & Carbon source utilization: & \\
Cellulose decomposition & - & D-glucose & + \\
Starch hydrolysis & + & Sucrose & + \\
Gelatin hydrolysis & + & L-arabinose & + \\
Nitrate reduction & + & Starch & + \\
$\mathrm{H}_{2}$ S production & - & Raffinose & - \\
\hline NaCl tolerance $(\%, w / v):$ & & D-fructose & + \\
5 & + & Maltose & + \\
7 & + & D-Xylose & + \\
10 & - & Galactose & + \\
\hline Growth temperature $\left({ }^{\circ} \mathrm{C}\right):$ & & D-mannitol & + \\
20 & + & Inositol & + \\
28 & + & L-rhamnose & - \\
37 & + & & \\
50 & - &
\end{tabular}

\section{3. $16 S$ rRNA Sequence Analysis}

A partial 16S rRNA gene sequence (1435 nucleotides) of strain STZ was determined and deposited with accession number MH753660 in the GenBank database. Comparative 16S rRNA gene sequence analysis using BLAST showed that the strain could be classified as a member of the genus Streptomyces and shared high sequence identity (99.37\%) with Streptomyces ahygroscopicus. A 16S rRNA gene-based phylogenetic tree was constructed with the maximum likelihood method with the different Streptomyces reference species available in the GenBank database (Figure 2). Phylogenetic analysis indicated that strain STZ closely clustered with the strain Streptomyces ahygroscopicus (accession number EU273553). 


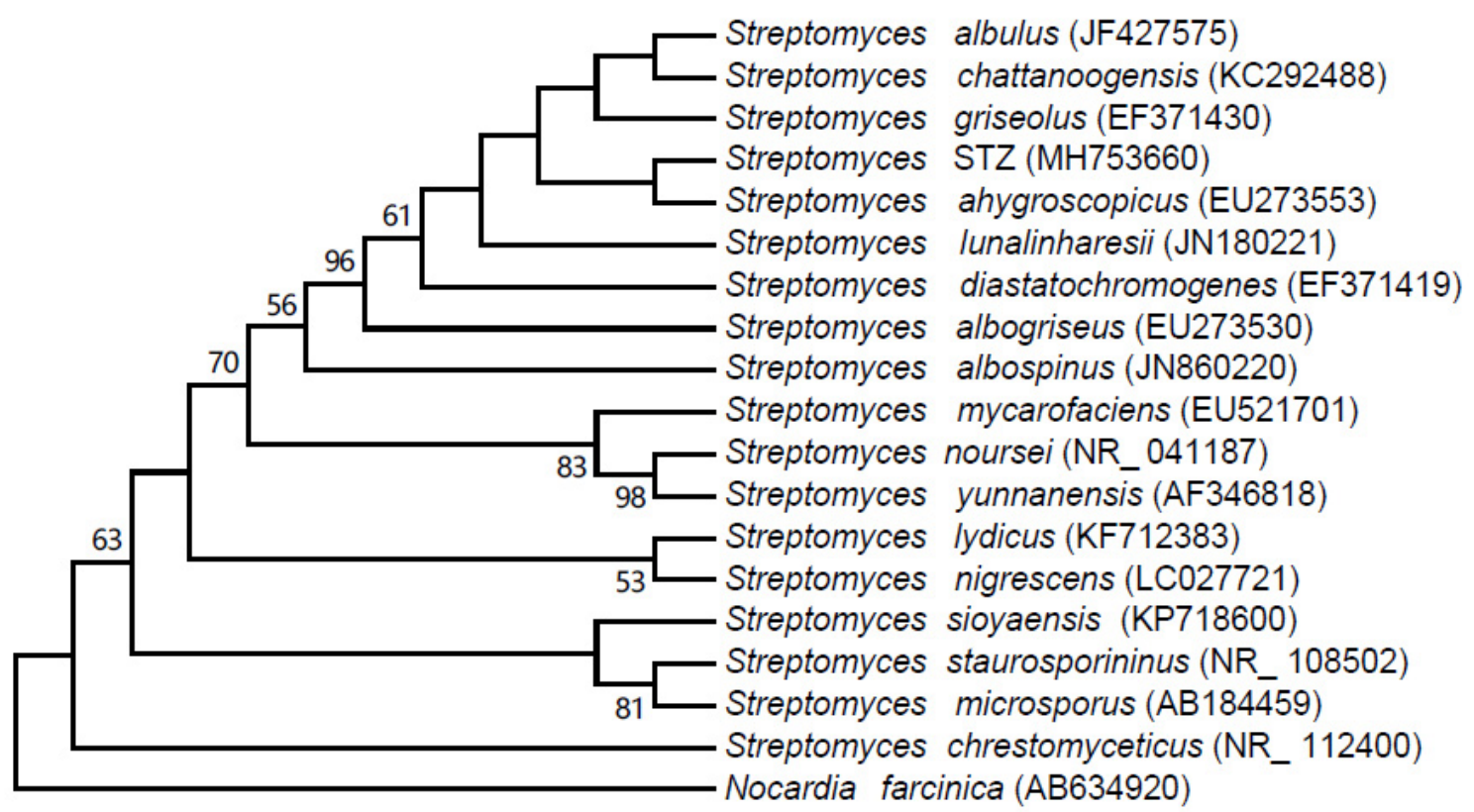

Figure 2. Phylogenetic analysis based on 16S rRNA gene sequences of Streptomyces STZ and species of the genus Streptomyces using the maximum likelihood method. Numbers on branch nodes are bootstrap values (1000 replicates).

\subsection{Purification and Structure Elucidation of the Pure Compound}

A pure compound was obtained from the fermentation broth of strain STZ after separation and purification procedures, the compound with faint yellow powder and slight bitter taste. The IR spectrum of the compound showed strong fluorescent (Figure 3). In the IR spectrum, amino group stretching vibration was observed at $3246 \mathrm{~cm}^{-1}$, alkyl group stretching vibration at $2931-3072 \mathrm{~cm}^{-1}$, carbonyl group stretching vibration at $1668 \mathrm{~cm}^{-1}$; peaks at 1560 and $651 \mathrm{~cm}^{-1}$ were assigned to in-plane and out-of-plane bending vibration absorption of amino groups, respectively. Intriguingly, the spectrum was generally consistent with the previously reported IR spectrum of $\varepsilon$-PL [15].

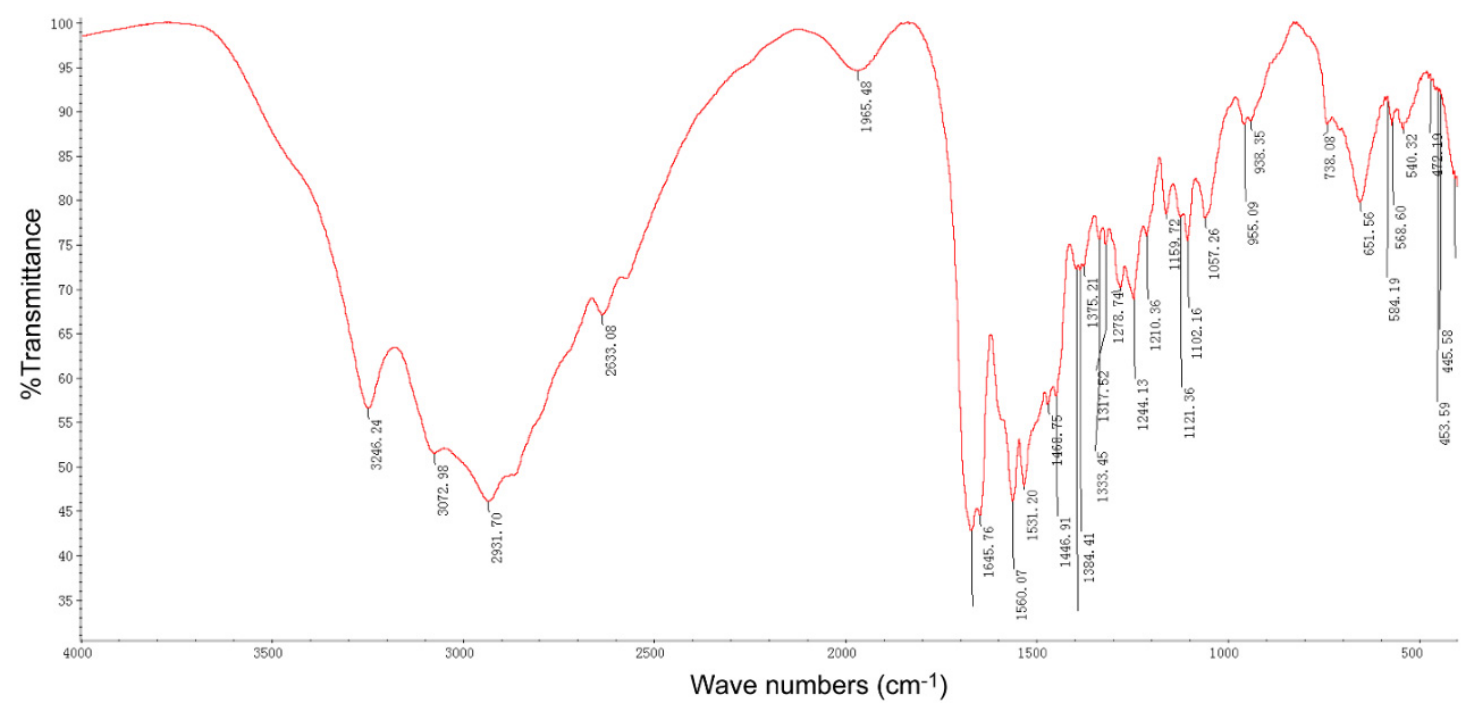

Figure 3. IR spectrum of the pure active compound isolated from Streptomyces STZ.

The ${ }^{1} \mathrm{H}-\mathrm{NMR}$ spectrum showed nine $\mathrm{H}$ signals in the higher field $(<6 \mathrm{ppm})$, which were attributable to the chemical shift of protons on the saturated sp3 carbon atom (Figure $4 \mathrm{~A}$ ). ${ }^{13} \mathrm{C}-\mathrm{NMR}$ and DEPT spectra showed six carbon signals (Figure 4B), of which there were one quaternary carbon, 
one tertiary carbon and four secondary carbon carbons. H-HCOSY experiment showed $81.385-1.439$ (C4-H) was correlated with $81.866-1.921(\mathrm{C} 3-\mathrm{H})$ and $\delta 1.556-1.627(\mathrm{C} 5-\mathrm{H}) ; \delta 1.556-1.627(\mathrm{C} 5-\mathrm{H})$ was correlated with $81.385-1.439(\mathrm{C} 4-\mathrm{H})$ and $83.237-3.271(\mathrm{C} 6-\mathrm{H})$; $81.866-1.921(\mathrm{C} 3-\mathrm{H})$ was correlated with 81.385-1.439 (C4-H) and $83.951-3.984(\mathrm{C} 2-\mathrm{H}) ; 83.237-3.271(\mathrm{C} 6-\mathrm{H})$ was correlated with $81.556-1.627$ (C5-H); 83.951-3.984 (C2-H) was correlated with 81.866-1.921 (C3-H) (Figure 4C). HSQC spectrum showed $\delta 21.70$ (C4) had a correlation with $\delta 1.385-1.439$ (C4-H); $\delta 27.92$ (C5) had a correlation with 81.556-1.627 (C5-H); 830.52 (C3) had a correlation with $81.866-1.921(\mathrm{C} 3-\mathrm{H}) ; 839.11$ (C6) had a correlation with 83.237-3.271 (C6-H); and 853.27 (C2) had a correlation with 83.951-3.984 (C2-H) (Figure 4D). Results of HMBC spectrum indicated that $\delta 21.70$ (C4) long-range correlations with $83.951-3.984$ (C2-H), 83.237-3.271 (C6-H), 81.866-1.921 (C3-H), and 81.556-1.627 (C5-H); $827.92(\mathrm{C} 5)$ long-range correlation with $83.237-3.271(\mathrm{C} 6-\mathrm{H})$; 830.52 (C3) long-range correlations with $83.951-3.984(\mathrm{C} 2-\mathrm{H})$, $\delta 1.385-1.439(\mathrm{C} 4-\mathrm{H})$, and $\delta 1.556-1.627(\mathrm{C} 5-\mathrm{H}) ; \delta 39.11$ (C6) long-range correlations with $\delta 1.385-1.439$ (C4-H) and $\delta 1.556-1.627(\mathrm{C} 5-\mathrm{H}) ; \delta 53.27(\mathrm{C} 2)$ long-range correlation with $\delta 1.866-1.921(\mathrm{C} 3-\mathrm{H}) ; \delta 169.60$ (C1) long-range correlations with 83.951-3.984 (C2-H), 83.237-3.271 (C6-H) and 81.866-1.921 (C3-H) (Figure 4E).

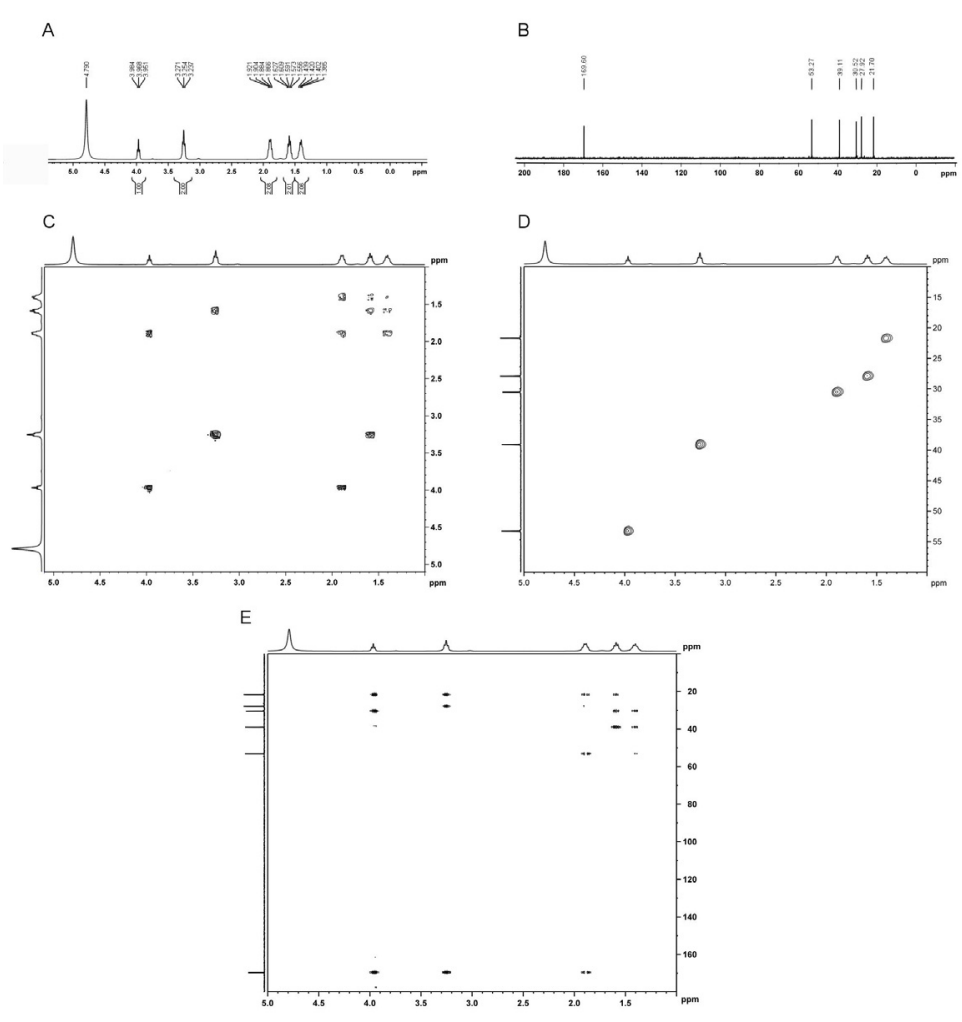

Figure 4. (A) ${ }^{1} \mathrm{H}-\mathrm{NMR}$ spectrum of the pure active compound produced by Streptomyces STZ; (B) ${ }^{13}$ C-NMR spectrum of the pure active compound produced by Streptomyces STZ; (C) H-HCOSY spectrum of the pure active compound produced by Streptomyces STZ; (D) HSQC spectrum of the pure active compound produced by Streptomyces STZ; (E) HMBC spectrum of the pure active compound produced by Streptomyces STZ.

The hydrolytes were analyzed by TLC with $\varepsilon$-PL and L-lysine standards used as controls. Results indicated that only lysine was present as an amino acid in the hydrolyte, which suggested that the purified compound produced by strain STZ was a polymer polymerized by L-lysine. Finally, the product was confirmed to be $\varepsilon$-PL that was in consistent with results from previous reports $[16,17]$. 


\subsection{MALDI-TOF-MS Analysis of the Active Compound}

As $\varepsilon$-PL belongs to homo-poly-amino acid with a chain of lysine residues (molecular weight: 146.19) linked by dehydration of water (molecular weight: 18.02), its molecular weight was calculable by the formula $146.19 \times n-18.02 \times(n-1)$, where $n$ is the number of lysine residues. The relative molecular mass of the active compound was estimated by MALDI-TOF-MS (Figure 5). The results indicated a series of $[\mathrm{M}+\mathrm{H}]^{+}$values that fit the estimated formula. The molecular mass was distributed in the range of 3454-4352 Da; the $m / z$ 4,096 represent the main molecular ion peak, and the $m / z 2049$ represent the double-charged ion peak. The polymerization degree was deduced to be in the range of $27-34$.

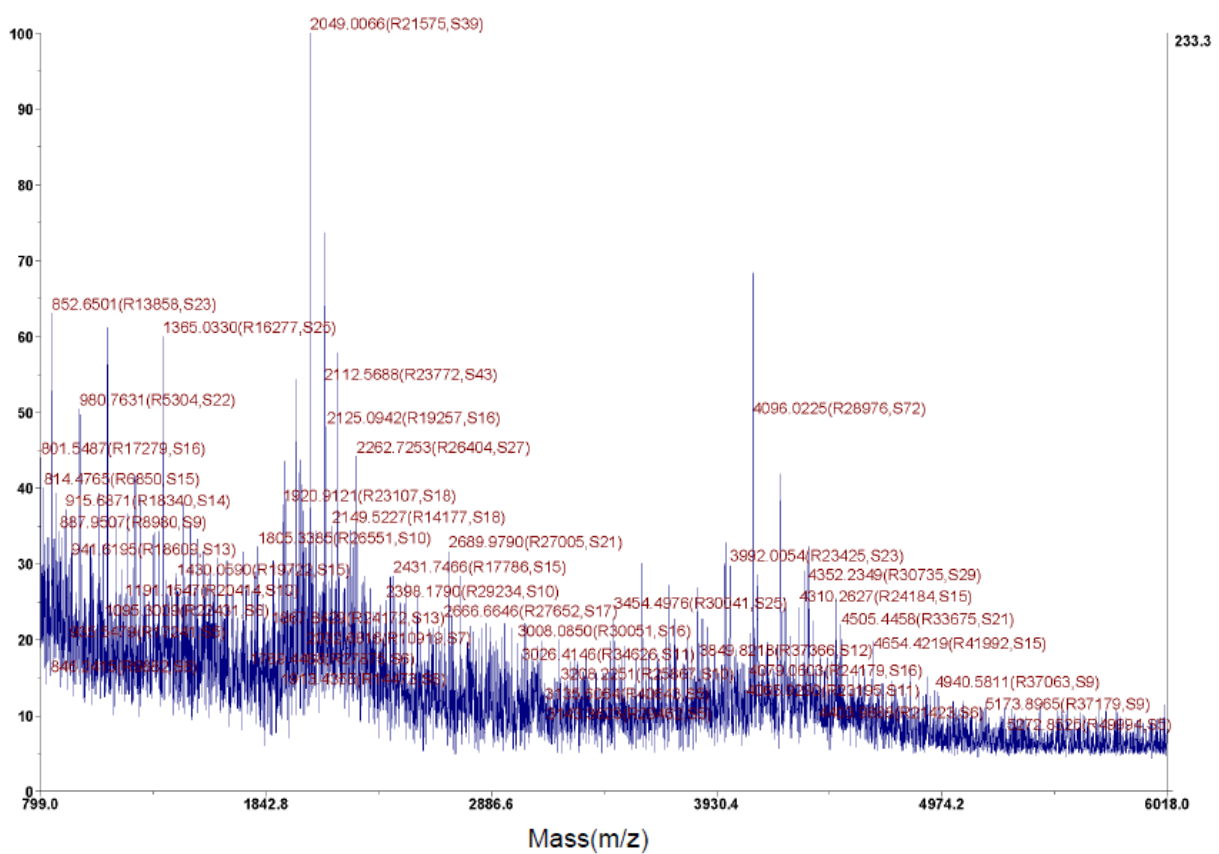

Figure 5. MALDI-TOF MS spectrum of the purified active product from Streptomyces STZ.

\subsection{Protective and Curative Activities of the Compound E-PL Against TMV}

The protective and curative effects of the purified compound $\varepsilon$-PL against TMV were tested at two concentrations using the half-leaf method. The results showed that compound $\varepsilon$-PL exhibited significant protective activity $(71.4 \pm 1.7 \%$ at $500 \mu \mathrm{g} / \mathrm{mL}$ and $84.2 \pm 3.2 \%$ at $1000 \mu \mathrm{g} / \mathrm{mL})$ and curative activity $(59.3 \pm 2.9 \%$ at $500 \mu \mathrm{g} / \mathrm{mL}$ and $68.7 \pm 3.4 \%$ at $1000 \mu \mathrm{g} / \mathrm{mL}$, respectively) against TMV (Table 2).

Table 2. Protection and curation effect of active compound against TMV.

\begin{tabular}{ccc}
\hline Compound Treatment & Protective Effect & Curative Effect \\
\hline $500 \mu \mathrm{g} / \mathrm{mL}$ & $71.4 \pm 1.7 \%$ & $59.3 \pm 2.9 \%$ \\
$1000 \mu \mathrm{g} / \mathrm{mL}$ & $84.2 \pm 3.2 \%$ & $68.7 \pm 3.4 \%$ \\
\hline
\end{tabular}

\section{Discussion}

The identification of easily biodegradable and ecofriendly compounds to meet the ongoing demand for novel antiviral agents, especially those produced by Streptomyces species, has increased in recent years.

In this study, the morphological, physiological, and biochemical properties and the phylogenetic evaluation suggest that the Streptomyces strain STZ belonged to Streptomyces ahygroscopicus. Finally, a pure active compound was isolated from the fermentation broth by various chromatographic techniques. Based on the analysis including TLC, UV spectroscopy, IR spectroscopy, HR-MAS-NMR 
spectroscopy and MALDI-TOF-MS, the compound was confirmed to be $\varepsilon$-PL, with molecular mass in the range of 3454-4352 Da and a degree of polymerization between 27-34.

$\varepsilon$-PL is an unusual biopolymer composed of L-lysine residues connected between $\alpha$-carboxyl and $\varepsilon$-amino groups, generally comprising 25-30 L-lysine residues [18]. $\varepsilon$-PL has previously been identified as positive substance in the culture supernatant of Streptomyces albulus from Dragendorff's reagent [18]. To date, increasing numbers of $\varepsilon$-PL producing microbes, such as Kitasatospora kifunense, Epichloe sp., Streptomyces aureofaciens, Streptomyces griseoaurantiacus, Streptomyces roseoverticillatus, Streptomyces diastatochromogenes, and Bacillus sp. have been reported [19-21].

$\varepsilon$-PL has been found to effectively inhibit broad ranges of microorganisms, including gram-positive and gram-negative bacteria such as Escherichia coli, Bacillus subtilis, Lactobacillus, Staphylococcus aureus, Botrytis cinerea, yeasts and certain types of viruses and phages [22-25]. In addition, $\varepsilon$-PL also has anticancer activity, which can inhibit the proliferation of the Hela S3 cells with a lethal concentration of LC71 and HepG2 cells with a lethal concentration of LC53, respectively [26]. Moreover, $\varepsilon$-PL is edible, water-soluble, biodegradable, and non-toxic toward to humans and the environment $[27,28]$. Due to the positive attributes described above, $\varepsilon$-PL has been approved by regulatory agencies of the United States, Japan, Korea, and Europe as a preservative in food manufacturing [29]. In addition, $\varepsilon$-PL has been specifically used as an emulsifying agent, a gene and drug carrier, an endotoxin-selective removal additive, and a cosmetic agent [30-32].

However, there have been no relevant reports on $\varepsilon$-PL as an anti-virus agent in agricultural applications. In this study, $\varepsilon$-PL produced by the Streptomyces ahygroscopicus was evaluated for the first time for its antiviral effects against plant virus. Whereas the precise molecular anti-viral mechanisms remained to be clarified by the future works. The present work also indicats there is potential for significant commercial applications of the compound $\varepsilon$-PL in the control of plant virus diseases.

\section{Materials and Methods}

\subsection{Sample Collection and Isolation of Streptomyces Strains}

A total of 34 soil samples were collected from Tianzhu Mountain in Shenyang, Liaoning Province, China $\left(41^{\circ} 48^{\prime} \mathrm{N}, 123^{\circ} 25^{\prime} 48^{\prime \prime} \mathrm{E}\right)$. The soil samples were air dried for 7 days at room temperature. Streptomyces strains were isolated by the standard dilution plate method on Gause's synthetic agar medium. $2.5 \mathrm{~mL}$ of $\mathrm{K}_{2} \mathrm{Cr}_{2} \mathrm{O}_{7}$ solution (1.775 g/L) was added to $100 \mathrm{~mL}$ medium as antifungal agent [33]. The cultures were incubated at $28{ }^{\circ} \mathrm{C}$ for 21 days. Single colonies were selected and purified 5 times. The purified cultures were maintained on slopes at $4{ }^{\circ} \mathrm{C}$ and suspended in a sterile glycerol solution $25 \%(w / v)$ at $-80{ }^{\circ} \mathrm{C}$ for further study.

\subsection{Fermentation}

The composition of the seed and fermentation medium was as follows: $50 \mathrm{~g} / \mathrm{L}$ glucose, $10 \mathrm{~g} / \mathrm{L}$ $(\mathrm{NH} 4)_{2} \mathrm{SO}_{4}, 5 \mathrm{~g} / \mathrm{L}$ yeast extract, $0.5 \mathrm{~g} / \mathrm{L} \mathrm{MgSO}_{4} \cdot 7 \mathrm{H}_{2} \mathrm{O}, 1.4 \mathrm{~g} / \mathrm{L} \mathrm{K}_{2} \mathrm{HPO}_{4}, 0.04 \mathrm{~g} / \mathrm{L} \mathrm{ZnSO}_{4} \cdot 7 \mathrm{H}_{2} \mathrm{O}$ and $0.03 \mathrm{~g} / \mathrm{L} \mathrm{FeSO}_{4} \cdot 7 \mathrm{H}_{2} \mathrm{O}$, and $\mathrm{pH}$ 6.8. The test strains were inoculated on the ISP3 medium and incubated at $28{ }^{\circ} \mathrm{C}$ for 7 days. Two spore cakes ( $5 \mathrm{~mm}$ in diameter) were removed and inoculated into a $250 \mathrm{~mL}$ flask containing $50 \mathrm{~mL}$ of seed medium. The seed cultures were grown at $28{ }^{\circ} \mathrm{C}$ at an agitation speed of $180 \mathrm{rpm}$ for $24 \mathrm{~h}$. Subsequently, seed cultures were inoculated aseptically into $250 \mathrm{~mL}$ flasks containing $50 \mathrm{~mL}$ of fermentation medium at a final concentration of $6 \%$. The fermentation was carried out on a rotary shaker (Shanghai Zhichu Instruments, Shanghai, China) at an agitation speed of $180 \mathrm{rpm}$ at $28^{\circ} \mathrm{C}$ for $72 \mathrm{~h}$. Biomass was separated from the growth medium by centrifugation at $8000 \mathrm{rpm}$ for $15 \mathrm{~min}$. The supernate was stored at $4{ }^{\circ} \mathrm{C}$ for subsequent use.

\subsection{Anti-TMV Activity Screening of Streptomyces Strains}

Nicotiana glutinosa at the 6-8 leaf stage were used as local lesion exhibiting host plants inoculated with TMV, which was maintained on Nicotiana tabacum cv. K326. TMV virions were purified 
according to Gooding's method [34]. The purified virus was diluted to $30 \mu \mathrm{g} / \mathrm{mL}$ with $0.01 \mathrm{M}$ phosphate-buffered saline (PBS) before use. Test of anti-TMV activity was carried out by the half-leaf method as described [35]. The culture filtrate was diluted five times and equally mixed with TMV $(30 \mu \mathrm{g} / \mathrm{mL})$. After $30 \mathrm{~min}$, the mixture was mechanically inoculated onto the left side of N. glutinosa leaves and a mixture of distilled water and TMV was inoculated onto the right side of the same leaf as a control. Each inoculated leaf was washed with water after $10 \mathrm{~min}$. N. glutinosa were cultivated at $25{ }^{\circ} \mathrm{C}$. The numbers of local lesions were recorded 3-4 days after inoculation. Three replicates were conducted to ensure the reliability of the results. The inhibitory rate was calculated according to the following formula: Inhibition rate $(\%)=[(\mathrm{C}-\mathrm{T}) / \mathrm{C}] \times 100 \%$. Where $\mathrm{T}$ is the average number of local lesions with culture filtrate treatment and $\mathrm{C}$ is the average number of local lesions of the control.

\subsection{Taxonomic Characterization of the Strain STZ}

Culture features were investigated on various international Streptomyces Project (ISP) media and Bennett's agar [36,37]. The color of mycelia, the degree of growth and other features were recorded following incubation at $28^{\circ} \mathrm{C}$ for 14 days. Analyses for the production of $\mathrm{H}_{2} \mathrm{~S}$ liquefaction of gelatin, reduction of nitrate, hydrolysis of starch, cellulose and utilization of carbon, nitrate reduction reaction, salt tolerance, and ability to grow at different temperatures were carried out as previously described [38-40].

Genomic DNA from strain STZ was extracted using the method as described [41]. Partial sequence of the $16 \mathrm{~S}$ rRNA gene was amplified by PCR using the universal primers 27F (5'-AGAGTTTGATCCTGGCTCAG-3') and 1492R (5'-TACCTTGTTACGACTT-3') [42]. The PCR reaction was carried out with an initial denaturation at $94{ }^{\circ} \mathrm{C}$ for 4 min followed by 30 cycles of denaturation at $94{ }^{\circ} \mathrm{C}$ for $1 \mathrm{~min}$, annealing at $55{ }^{\circ} \mathrm{C}$ for $1 \mathrm{~min}$, and extension at $72{ }^{\circ} \mathrm{C}$ for $2 \mathrm{~min}$. After the cycling, a final extension at $72{ }^{\circ} \mathrm{C}$ for $7 \mathrm{~min}$ was performed. The PCR product was purified and integrated into the vector pMD19-T (Takara, Japan) and the 16S rRNA gene was sequenced by Sangon Biotech Co., Ltd. (Shanghai, China).

The sequence data was deposited in GenBank (no. MH753660) and compared with sequences using the nucleotide BLAST (http:/ / www.ncbi.nlm.nih.gov/BLAST) in GenBank. Multiple alignments of the sequence and the closest matches retrieved from the database and the phylogenetic tree were constructed with Mega program version 7.0.14 using the maximum likelihood method [43].

\subsection{Separation and Purification}

For isolation of the anti-TMV compound from the culture of strain STZ, bioassay based on anti-TMV activity was performed using the half-leaf method in every process during purification. Method to assess the purification of the active compound was as below: fermentation broth was centrifuged at $8000 \mathrm{rpm}$ for $15 \mathrm{~min}$ to remove mycelium, the supernate was adjusted to $\mathrm{pH} 8.5$ with $2 \mathrm{M} \mathrm{NaOH}$ and subjected to heating treatment at $65^{\circ} \mathrm{C}$ for $1 \mathrm{~h}$. Thereafter, the solution was filtered through filter paper to remove the precipitation. The filtrate was adsorbed onto an ion exchange column filled with Amberlite IRC-50 resin, deionized water was employed for washing resin, and $0.1 \mathrm{M}$ $\mathrm{HCl}$ was used to elute active compound from resin. Subsequently, the pigment was removed by column chromatography on SX-8 macroporous adsorption resin. The active fractions were concentrated under vacuum and further purified by column chromatography using Sephadex G-25. Finally, the pure product was obtained by precipitation with acetone.

\subsection{Structure Determination for the Pure Compound}

The infrared (IR) spectroscopy spectrum was recorded using a $\mathrm{KBr}$ disk on a Nicolet 6700 Fourier infrared spectrometer (Thermo Fisher Scientific, Waltham, MA, USA). Proton NMR $\left({ }^{1} \mathrm{H}-\mathrm{NMR}\right)$ and a carbon NMR $\left({ }^{13} \mathrm{C}-\mathrm{NMR}\right)$ spectra of the compound were ascertained via AVANCE DRX-400 MHz NMR spectroscopy (Bruker, Rheinstetten, Germany). Additional heteronuclear multiple bond correlation (HMBC) spectroscopy, $\mathrm{H}-\mathrm{H}$ correlation spectroscopy ( $\mathrm{H}-\mathrm{H}$ COSY) and heteronuclear 
singular quantum correlation (HSQC) analyses were also performed for structure elucidation. The amino acid composition of the pure compound was analyzed via hydrochloric acid hydrolysis and thin-layer chromatography (TLC). A sample $(1 \mathrm{~mL})$ of the pure product was hydrolyzed completely by heating in $6 \mathrm{~mol} / \mathrm{L} \mathrm{HCl}$ at $110{ }^{\circ} \mathrm{C}$ for $20 \mathrm{~h}$. The reaction product was analyzed by TLC (developer, n-butanol-acetic acid-water-methanol at 3:1:2:2 relative amounts; detection, $0.5 \%$ ninhydrin reagent in ethanol) with $\varepsilon$-PL and lysine standards as controls.

\subsection{Molecular Mass Determination of the Pure Compound}

Mass spectrometry (MS) of the pure product was determined by matrix-assisted laser desorption ionization-time-of-flight mass spectrometry MS (MALDI-TOF-MS) using an AB TOF 5800 model (AB Sciex, Chicago, IL, USA). As a matrix, $\alpha$-cyano-4-hydroxycinnamic acid was used (CHCA).

\subsection{Protection Effect of the Compound Against TMV In Vivo}

The purified compound was solubilized in PBS and sprayed on the left side leaves with 6-8 leaf stage old N. glutinosa, then PBS buffer was used as a control on the right side of leaves. The leaves were then inoculated by the $100 \mu \mathrm{L}$ virions of TMV at concentration of $30 \mathrm{ng} / \mu \mathrm{L}$ after $12 \mathrm{~h}$. The local lesions and inhibition rates were calculated at 3-4 days. Each assays were repeated for at least 3 times.

\subsection{Curative Effect of the Compound Against TMV In Vivo}

The leaves on $N$. glutinosa of the same age were selected and inoculated with the $100 \mu \mathrm{L} 30 \mathrm{ng} / \mu \mathrm{L}$ TMV virions. After $12 \mathrm{~h}$, the compound solution was sprayed on the left side and the PBS buffer was sprayed on the right side for control. The local lesion numbers were then recorded 3-4 days after inoculation.

Author Contributions: Conceptualization, Y.W. and M.A.; Data curation, Z.X. and M.A.; Funding acquisition, Y.W.; Investigation, J.C. and H.L.; Methodology, J.C. and Z.X.; Resources, X.Z.; Software, H.L. and X.Z.; Writing—original draft, J.C.; Writing—review \& editing, Y.W. and M.A.

Funding: National Key R\&D Program of China (2017YFD0201104); Key Science and Technology Projects of China Tobacco Corporation [2016(259)]; Natural Science Foundation of China Nos (31401710); National Key R\&D Program of China (2017YFE04900).

Conflicts of Interest: The authors declare no conflict of interest.

\section{References}

1. Scholthof, K.G.; Adkins, S.; Czosnek, H.; Palukaitis, P.; Jacquot, E.; Hohn, T.; Hohn, B.; Saunders, K.; Candresse, T.; Ahlquist, P.; et al. Top 10 plant viruses in molecular plant pathology. Mol. Plant Pathol. 2011, 12, 938-954. [CrossRef] [PubMed]

2. Fraile, A.; Garcia-Arenal, F. Tobamoviruses as Models for the Study of Virus Evolution. Adv. Virus Res. 2018, 102, 89-117. [PubMed]

3. Roossinck, M.J. Plants, viruses and the environment: Ecology and mutualism. Virology 2015, 479-480, 271-277. [CrossRef] [PubMed]

4. Seiber, J.N. Sustainability and agricultural and food chemistry. J. Agric. Food Chem. 2011, 59, 1-21. [CrossRef] [PubMed]

5. Han, Y.G.; Luo, Y.; Qin, S.R.; Xi, L.; Wan, B.; Du, L.F. Induction of systemic resistance against tobacco mosaic virus by Ningnanmycin in tobacco. Pestic. Biochem. Physiol. 2014, 111, 14-18. [CrossRef] [PubMed]

6. Zhao, X.X.; Wu, Y.H.; Du, C.M.; Song, Y. Control of tomato virus disease with Cytosintetidemycin. Pesticides 2004, 43, 534-536.

7. Zhu, C.Y.; Wu, Y.H.; Wang, C.M.; Zhao, X.X.; Wang, Y.H.; Du, C.M. Inhibition of Cytosinpeptidemycin on tobacco mosaic virus. Plant Prot. 2005, 31, 52-54.

8. Yu, L.; Wang, W.L.; Zeng, S.; Chen, Z.; Yang, A.M.; Shi, J.; Zhao, X.Z.; Song, B.A. Label-free quantitative proteomics analysis of Cytosinpeptidemycin responses in southern rice black-streaked dwarf virus-infected rice. Pestic. Biochem. Physiol. 2018, 147, 20-26. [CrossRef] 
9. Tan, Q.W.; Fang, P.H.; Ni, J.C.; Gao, F.L.; Chen, Q.J. Metabolites Produced by an Endophytic Phomopsis sp. and their anti-TMV activity. Molecules 2017, 22, 2073. [CrossRef]

10. Han, L.R.; Zhang, G.Q.; Miao, G.P.; Zhang, X.; Feng, J.T. Streptomyces kanasensis sp. nov., an antiviral glycoprotein producing Streptomyces isolated from forest soil around Kanas Lake of China. Curr. Microbiol. 2015, 71, 627-631. [CrossRef] [PubMed]

11. Shima, S.; Matsuoka, H.; Iwamoto, T.; Sakai, H. Antimicrobial action of epsilon-poly-L-lysine. J. Antibiot. 1984, 37, 1449-1455. [CrossRef] [PubMed]

12. Neda, K.; Sakurai, T.; Takahashi, M.; Ashiuchi, M.; Ohgushi, M. Two-generation reproduction study with teratology test of $\varepsilon$-poly-L-lysine by dietary administration in rats. Jpn. Pharmacol. Ther. 1999, 27, 1139-1159.

13. Hiraki, J. Basic and applied studies on e-poly-L-lysine. J. Antibact. Antifung. Agents 1995, 23, 349-354.

14. Hamano, Y. Occurrence, biosynthesis, biodegradation, and industrial and medical applications of a naturally occurring epsilon-poly-L-lysine. Biosci. Biotechnol. Biochem. 2011, 75, 1226-1233. [CrossRef]

15. Shima, S.; Sakai, H. Poly-L-lysine Produced by Streptomyces. Part III. Chemical Studies. Agric. Biol. Chem. Chem. 1981, 45, 2503-2508. [CrossRef]

16. Maeda, S.; Kunimoto, K.K.; Sasaki, C.; Kuwae, A.; Hanaic, K. Characterization of microbial poly ( $\varepsilon$-L-lysine) by FT-IR, Raman and solid state ${ }^{13}$ C-NMR spectroscopies. J. Mol. Struct. 2003, 655, 149-155. [CrossRef]

17. Maeda, S.; Mori, T.; Sasaki, C.; Kunimoto, K.; Kuwae, A.; Hanai, K. Structural investigation of microbial poly ( $\varepsilon$-L-lysine) derivatives with azo dyes by solid-state ${ }^{13} \mathrm{C}$ and ${ }^{15} \mathrm{~N}$ NMR. Polym. Bull. 2005, 53, $259-267$. [CrossRef]

18. Shima, S.; Sakai, H. Polylysine produced by Streptomyces. Agric. Biol. Chem. 1977, 41, 1807-1809. [CrossRef]

19. Nishikawa, M.; Kobayashi, K. Streptomyces roseoverticillatus produces two different poly(amino acid)s: Lariat-shaped gamma-poly (L-glutamic acid) and epsilon-poly(L-lysine). Microbiology 2009, 155, 2988-2993. [CrossRef] [PubMed]

20. Takehara, M.; Hibino, A.; Saimura, M.; Hirohara, H. High-yield production of short chain length poly ( $\varepsilon$-L-ly sine) consisting of 5-20 residues by Streptomyces aureofaciens, and its antimicrobial activity. Biotechnol. Lett. 2010, 32, 1299-1303. [CrossRef] [PubMed]

21. Li, S.; Tang, L.; Chen, X.S.; Liao, L.J.; Li, F.; Mao, Z.G. Isolation and characterization of a novel $\varepsilon$-poly-L-lysine producing strain: Streptomyces griseofuscus. J. Ind. Microbiol. Biotechnol. 2011, 38, 557-563. [CrossRef] [PubMed]

22. Li, Y.Q.; Han, Q.; Feng, J.L.; Tian, W.L.; Mo, H.Z. Antibacterial characteristics and mechanisms of $\varepsilon$-poly-lysine against Escherichia coli and Staphylococcus aureus. Food Control 2014, 43, 22-27. [CrossRef]

23. Li, H.; He, C.; Li, G.G.; Zhang, Z.Q.; Li, B.Q.; Tian, S.P. The modes of action of epsilon-polylysine (ع-PL) against Botrytis cinerea in jujube fruit. Postharvest Biol. Technol. 2019, 147,1-9. [CrossRef]

24. Ye, R.S.; Xu, H.Y.; Wan, C.X.; Peng, S.S.; Wang, L.J.; Xu, H.; Aguilar, Z.; Xiong, Y.H.; Zeng, Z.L.; Wei, H. Antibacterial activity and mechanism of action of e-poly-L-lysine. Biochem. Biophys. Res. Commun. 2013, 439, 148-153. [CrossRef] [PubMed]

25. Shima, S.; Fukuhara, Y.; Sakai, H. Inactivation of bacteriophages by $\varepsilon$-poly-L-lysine produced by Streptomyces. Agric. Biol. Chem. 1982, 46, 1917-1919.

26. El-Sersy, N.A.; Abdelwahab, A.E.; Abouelkhiir, S.S.; Abou-Zeid, D.M.; Sabry, S. Antibacterial and anticancer activity of $\varepsilon$-poly-L-lysine ( $\varepsilon-\mathrm{PL}$ ) produced by a marine Bacillus subtilis sp. J. Basic Microbiol. 2012, 52, 513-522. [CrossRef]

27. Hiraki, J. $\varepsilon$-Polylysine: Its development and utilization. Fine Chem. 2000, 29, 18-25.

28. Hiraki, J.; Ichikawa, T.; Ninomiya, S.; Seki, H.; Uohama, K.; Seki, H.; Kimura, S.; Yanagimoto, Y.; Barnett, J.W. Use of ADME studies to confirm the safety of $\varepsilon$-polylysine as a preservative in food. Regul. Toxicol. Pharmacol. 2003, 37, 328-340. [CrossRef]

29. Yamanaka, K.; Hamano, Y. Biotechnological production of poly-epsilon-L-lysine for food and medical applications. In Amino-Acid Homopolymers Occurring in Nature; Hamano, Y., Ed.; Springer: Berlin, Germany, 2010; pp. 61-75.

30. Shih, I.L.; Van, Y.T.; Shen, M.H. Biomedical applications of chemically and microbiologically synthesized poly (glutamicacid) and poly(lysine). Mini-Rev. Med. Chem. 2004, 4, 179-188. [CrossRef]

31. Shih, I.L.; Shen, M.H.; Van, Y.T. Microbial synthesis of poly ( $\varepsilon$-lysine) and its various applications. Bioresour. Technol. 2006, 97, 1148-1159. [CrossRef] [PubMed] 
32. Shukla, S.C.; Singh, A.; Pandey, A.K.; Mishra, A. Review on production and medical applications of $\varepsilon$-polylysine. Biochem. Eng. J. 2012, 65, 70-78. [CrossRef]

33. Tsao, P.H.; Leben, C.; Keitt, G.W. An enrichment method for isolating Streptomyces that produce diffusible antifungal antibiotics. Phytopathology 1960, 50, 88-89.

34. Gooding, G.V.; Hebert, T.T. A simple technique for purification of tobacco mosaic virus in large quantities. Phytopathology 1967, 57, 1285-1287. [PubMed]

35. Song, B.A.; Zhang, H.P.; Wang, H.; Yang, S.; Jin, L.H.; Hu, D.Y. Synthesis and antiviral activity of novel chiral cyanoacrylate derivatives. J. Agric. Food Chem. 2005, 53, 7886-7891. [CrossRef] [PubMed]

36. Shirling, E.B.; Gottlieb, D. Methods for characterisation of Streptomyces species. Int. J. Syst. Bacteriol. 1966, 16, 313-340. [CrossRef]

37. Jones, K.L. Fresh isolates of Streptomyces in which the presence of sporogenous aerial mycelia is a fluctuating characteristic. J. Bacteriol. 1949, 57, 141-145. [PubMed]

38. Waksman, S.A. The Streptomyces: Their nature, occurrence, activities, and importance. J. Am. Med. Assoc. 1950, 144, 505-506.

39. Gottlieb, D. An evolution of criteria and procedures used in the description and bcharacterization of Streptomyces. Appl. Microbiol. 1961, 9, 55-65. [PubMed]

40. Holding, A.J.; Collee, J.G. Chapter I routine biochemical tests. Methods Microbiol. 1971, 6A, 1-32.

41. Sharma, A.D.; Singh, J. A nonenzymatic method to isolate genomic DNA from bacteria and Streptomyces. Anal. Biochem. 2005, 337, 354-356. [CrossRef]

42. Frank, J.A.; Reich, C.I.; Sharma, S.; Weisbaum, J.S.; Wilson, B.A.; Olsen, G.J. Critical evaluation of two primers commonly used for amplification of bacterial 16S rRNA gene. Appl. Environ. Microbiol. 2008, 74, 2461-2470. [CrossRef] [PubMed]

43. Kumar, S.; Stecher, G.; Tamura, K. MEGA7: Molecular Evolutionary Genetics Analysis Version 7.0 for Bigger Datasets. Mol. Biol. Evol. 2016, 33, 1870-1874. [CrossRef] [PubMed]

Sample Availability: Sample of the compound is available from the authors.

(c) 2019 by the authors. Licensee MDPI, Basel, Switzerland. This article is an open access article distributed under the terms and conditions of the Creative Commons Attribution (CC BY) license (http://creativecommons.org/licenses/by/4.0/). 